a new design of ash pan for railway locomotives for use with inferior coal, while the British Coke Research Association is seeking the best methods for disposing of liquid effluent from coke-oven plants and estab. lishing the standards of purification required for effluents which are disposed of to rivers and sewers.

The automatic hardening machine designed by the Cutlery Research Council to reduce the labour required for the operation to 25 per cent of that needed for the conventional method represents the Council's first major attempt at mechanization. Machines developed for the classification of fine powders, depending on the opposing action of centrifugal force and inward air-drag, have been used by the Research Association of British Flour-Millers to make cuts in flour at production-rates of commercial interest, giving, for example, a higher protein half of better bread-making quality and the other half of better cake-making quality than the original flour. Largescale canning trials by the Fruit and Vegetable Canning and Quick Freezing Research Association indicate that the antibiotic, nisin, has potential application in controlling the spoilage of canned vegetables by heat-resistant thermophilic bacteria.

Besides devising apparatus to determine at any time the stage to which glass melting has proceeded, the British Glass Industry Research Association has given much attention to the role of instrumentation and automatic control of furnace conditions, while electronic methods devised by the Hosiery and Allied Trades Research Association have enabled lengths of stockings to be controlled automatically within very close limits. A simple investigation of flow in small open channels by the British Hydromechanies Research Association has permitted the designer to reduce the number of down pipes in a length of building by one-half and has also pointed to a slight modification of the outlet design which can double the capacity of the system.

The British Iron and Steel Research Association has applied the statistical technique of regression analysis to establish correlations between the many factors that affect the performance of blast furnaces, and the British Jute Trade Research Association has developed an anti-corrosive wrapping material for bright steel parts. The Motor Industry Research Association is investigating a promising method of reducing noise in vehicles by damping the vibration of body panels, and the work of the Research Association of British Paint, Colour and Varnish Manufacturers has included the structural features of paint films, the molecular make-up of the medium in film form and the character and disposition of the pigment particles.

An entirely new process for the production of paper pulp from graminaceous raw materials, devised by the British Paper and Board Industry Research Association, gives greatly increased yields, and the Printing, Packaging and Allied Trades Research Association continued its study of the hazards of transport and how packages stand up to them. The British Rayon Research Association has put on the market the warp tension balance, which enables the loom overlooker to control the incidence of repping, and an electronic tensiometer, for the correct setting of yarn spinning and processing machinery; and a study of productivity in the process of mastication and mixing by the Research Association of British Rubber Manufacturers has greatly increased production.

In its methodical tests on models of ocean-going merchant vessels, the British Shipbuilding Research Association is giving much attention to the problem of hull roughness. The Coil Spring Federation Research Organization is studying the effect of variations in manufacture and materials on the fatigue life of heavy suspension springs, and the British Steel Castings Research Association has started a long-range investigation on the factors determining the efficient utilization of oxygen in electric furnace steel-making. The Coal Tar Research Association has given particular attention to factors influencing the purification of naphthalene by fractionation and by crystallization.

\title{
AIRFLOW OVER MOUNTAINS
}

$I^{\mathrm{T}}$ has been recognized for many years that regular patterns of motion of a wave-like type may occur in the air flowing over and to the lee of mountain ranges. This seems to have been realized first from the clouds which--given suitable conditions of temperature and humidity - form in the ascending currents of the waves and which are more or less stationary although obviously situated in a strong wind. The rising and falling components of wind in these waves are of importance to aviation as they may cause the aircraft to rise, or more important, descend in a dangerous manner. They have frequently been used by glider pilots as a means of ascent. The wave patterns can occur at considerable distances above and beyond the mountain range responsible and must be distinguished from the irregular turbulent flow set up in the immediate vicinity of the peaks and steep parts of the mountains. The waves are most readily produced by long ranges transverse to the wind.

Much theoretical study has been devoted to the mechanics of the waves in the past twenty years, the most successful theory being due to Dr. R. S. Scorer of the Imperial College of Science and Technology,
London. Dr. Scorer's theory has been well verified by the experiences of aircraft pilots and other observations, so that it now appears justifiable for aviation weather forecasters to use it in attempting to predict the occurrence of waves.

Dr. Scorer showed that waves will form only if the vertical gradient of temperature and wind speed in the air to windward of the range are suitable. His theory in fact states that waves will form if the quantity termed $l^{2}$, which is given by:

$$
\frac{g}{T} \frac{\left(\Gamma+\frac{\mathrm{d} T}{\mathrm{~d} z}\right)}{U^{2}}-\frac{1}{U} \frac{\mathrm{d}^{2} U}{\mathrm{~d} z^{2}}
$$

(where $T$ is the absolute temperature, $\Gamma$ is the numerical value of the dry adiabatic lapse-rate, $U$ is the wind speed, and $Z$ the height), decreases with height. In fact, and fortunately, the difficult second term is of small account compared with the first term, which can be calculated with sufficient accuracy from observations.

From the formula, considering only the first term, it follows that waves are to be expected if the tem- 
perature gradient decreases (lapse-rate increasing, in the usual meteorological terminology) with height, or wind speed increases, or there is a suitable combination of both effects.

In Meteorological Report No. 18*, Mr. G. A. Corby of the Meteorological Office describes how Dr. Scorer's theory can be exploited by forecasters when advising pilots on the nature of the airflow over mountains. He gives a number of reports of waves encountered * Air Ministry : Meteorological Office. Meteorological Report
No. 18: Air Flow Over Mountains-Notes for Forecasters and Pilots. By G. A. Corby. Pp. ii + 53. (London: H.M. Stationery Office, 1957.) by aireraft, and shows how the occurrence of the waves in question was to be expected from the atmospheric structure. A suitable diagram for computing $l^{2}$ is given with instructions for its use in forecasting.

The report also contains diagrams of the flow of air in lee waves computed from the general theory and an account of such effects as the increase in liability to ice formation, given suitable air temperature and humidity, in the waves because the ascent of the air has the effect of lowering the height of the freezing-level. G. A. BuLL

\section{MOUNT STROMLO OBSERVATORY}

\section{REPORT FOR 1957}

$\mathrm{T}$ HE annual report of Mount Stromlo Observatory for $1957^{*}$ deals first with the transfer of the Observatory to the Australian National University on January 3, 1957, when the Commonwealth Observatory of the Department of the Interior officially ceased to exist. All the members of the scientific staff of the Observatory were transferred to the Department of Astronomy of the Research School of Physical Sciences of the Australian National University, the official name of the Observatory then becoming 'Mount Stromlo Observatory'. Arrangements were made not only to safeguard the financial status of the staff but also to protect an area of about $3 \frac{1}{2}$ square miles in which the Observatory buildings are situated "from invasion by industry, commerce or any development relating to the growth of the nearby capital city of Canberra".

Following the departure of Dr. R. v. d. R. Woollev in December 1955, Dr. A. R. Hogg assumed the post of acting director of Mount Stromlo Observatory, a position which he retained until Dr. Woolley's suceessor, Dr. B. J. Bok, took office in March 1957, and on his arrival became head of the newly formed Department of Astronomy at the Australian National University. Tribute is paid to the valuable work accomplished during Dr. Hogg's tenure of office, and on Dr. Bok's arrival he was appointed assistant director.

Tests of the 74-in. mirror by Dr. Hogg, with the assistance of Mr. K. Gottlieb, proved the existence of astigmatism in excess of the maximum permissible amount, and while steps are being taken to remedy this, the telescope during the interim is used for photoelectric, spectrographic and photographic work. Under Dr. Hogg's direction the mirror was successfully aluminized. The 50-in. Melbourne reflector has been overhauled in the Design Department and the workshop. Motorization of the fast motion in right ascension has been completed and provisions have been made for Selsyn repeater systems in both declination and right ascension. Other alterations have been made and an important work plan is well under way to replace the present $f / 2$ spherical primary with an $f / 4.5$ paraboloid and a conventional Cassegrain mirror for the entire system to operate at $f / 18$. The 30-in. Reynolds reflector, which continues to be in regular use, is overdue for a complete mechanical and electrical overhaul. Short notes appear on the other instruments, including the 20 -in. Catts reflector,

* Australian National University : Mount Stromlo Observatory. Annual Keport for the Year 1957. Pp. 22. (Canberra: Australian National UTiversity, 1958.) the 8-in. $f / 1$ Schmidt, and the photographic zenith tube, and considerable space has been devoted to Dr. T. Dunham's plans for a coudé spectrograph on the 74-in. reflector. The spectrograph will be enclosed in a housing with double walls $24 \mathrm{ft}$. long and $16 \mathrm{ft}$. wide, and air at constant temperature will circulate between the two layers of the wall, thereby avoiding thermal effects on the instrument.

Among other matters dealt with are observation of artificial Earth satellites. It is emphasized that Mount Stromlo Observatory is not officially involved in the observation of artificial satellites and the names of other institutions and also individuals are referred to in connexion with this work. Nevertheless, Sputnik $I$ was kept under observation, and later Dr. A. Przybylski carried out observations of other satellites and did a considerable amount of work on their orbits. He also issued duplicated copies of predicted times of observation which proved to be very reliable.

Eight vacation scholars selected from undergraduate students in physics and mathematics at the Universities of Melbourne, Adelaide, Queensland and Sydney were appointed for the summer months, and each scholar has been assigned as a special assistant to a staff member. These scholars hold weekly colloquia, attend weekly informal discussion meetings, and participate in the night observing, acting as night assistants on the 74-in. reflector during staff vacations. They live in University House, conduct the visitors around during the day-time and participate fully in many other Observatory activities. It is hoped that during 1958 the first appointments will be made to regular scholarships leading to the Ph.D. degree.

Public visits to the Observatory both by day and night have been remarkably popular; to accommodate the great demand for visits by night the Director has instituted a series of monthly visitors' nights, with an average attendance of 150 people, and on these nights most telescopes are open for inspection. Estimates of the number of visitors show that there have been about 3,500 day-time visitors, 500 Wednesday visitors and 1,000 visitors during the seven special evenings. A booklet has been issued which gives information about the Observatory and its work. A list of the names of the twenty-two members of the Observatory staff and a catalogue of papers published during 1957 appear at the end of the report. 